EPiC Series in Engineering
Volume 3, 2018, Pages 884-891
HIC 2018. 13th International
Conference on Hydroinformatics

\title{
Perception analysis of potable water service to users
}

\author{
Hansen Rodríguez, M.P. ${ }^{1}$, Rodríguez Varela, J.M. ${ }^{1}$, Antúnez Leyva, E. ${ }^{1}$, \\ Casados Prior, J.A. ${ }^{1}$, Gómez Lugo, L. ${ }^{1}$, Martínez Ocampo, G.A. ${ }^{1}$ y Laurel \\ Varela, Y. ${ }^{1}$ \\ ${ }^{1}$ Instituto Mexicano de Tecnología del Agua, Hydraulic Department; Urban Hydraulics Subsection, \\ Paseo Cuauhnáhuac 8532, Col. Progreso, Jiutepec, Morelos, 62550, México \\ phansen@tlaloc.imta.mx,manuel_rodriguez@tlaloc.imta.mx, eantunez@tlaloc.imta.mx, \\ jorgecasados@tlaloc.imta.mx, lgomez@tlaloc.imta.mx, gemaalin@tlaloc.imta.mx, \\ yenlav19@hotmail.com
}

\begin{abstract}
.
In Mexico, the regulatory framework does not obligate water utilities to report technical, administrative or financial information, nor are they required to have a management-indicator system to help them evaluate the service that they offer. In 2005 the Mexican Water Technology Institute (IMTA) started a voluntary participation program for tracking water utility management indicators (known as PIGOO for its Spanish initials) which has permitted participants to know what their own performance and evolution is. These results, however, do not represent what users think of the potablewater service so two additional studies were carried out to analyze the quality perception users have of their water-utility company. One permits the rating of the public image of the institution, that is to say, how a user is treated upon showing up in the offices to make a complaint or to file some procedure and another that evaluates the quality perception of the service that water utilities deliver to homes. These results will contribute towards identifying improvement areas in the service to users and the rating they give in turn, can help further the development and self-sustainability of water utilities.
\end{abstract}

\section{Introduction}

Mexico, officially named the United Mexican States, is a country located in the meridianal part of the North American continent, its capital is Mexico City. Politically, it is a democratic republic, representative and federal, comprised of 32 federative entities.

The Mexican territory has a surface of $1964375 \mathrm{~km}^{2}$, making it the fourteenth largest country in the world and third largest in Latin America. 
Mexico is the eleventh most populated country in the world, with an estimated 119 million inhabitants in 2015, the main percentage of which live in urban areas (77\%), the remaining 23\% reside in rural areas, as of December 2015 this population of nine million does not have potable water service and 10.2 million lack sewerage service (CONAGUA, 2016).

The provision of potable water, sewerage and treatment service in Mexico, in accordance to article 115 of the Political Constitution of the United Mexican States, is handled directly by the municipal governments by way of a water utility, which operate as decentralized organizations of the municipalities, subject to compliance with official regulations.

For a water utility to be able to provide potable water and treatment services, municipal authorities must expedite an official decree in which it is vested with the attribution of managing water resources and operating the technical infrastructure necessary for the fulfillment of this role, additionally, it is given the concession to extract, make use of and distribute water in the geographic area and determined reach of the application it was created for (municipal, urban region, or rural region)

According to the economic censuses published in 2009 by the National Statistics and Geographic Institute (INEGI, 2009), in Mexico, for the task of carrying out catchment, potabilization, delivery, distribution, recollection, treatment or disposition of water, there are 2,517 water-utility operators. In the urban zones there are 1,302, of which 207 are participating this year in PIGOO accounting for over $15 \%$ of all water utilities.

The Mexican Water Technology Institute (IMTA, 2017), runs a management-indicator program for water utilities (PIGOO), it is important to note that from the year 2005 to 2017 the number of participating water utilities has increased from 50 to 207, which demonstrates the interest being taken in the program, these participants provide service to $56 \%$ of the population in Mexico. The number of management indicators has gone up as well, from 12 to 29. The information for participating water utility companies can be found published on the website: http://www.pigoo.gob.mx/, along with an option to consult the information via a mobile application for the Android operating system.

The prime objective of the project is: "To qualify and monitor through an assortment of strategic indicators on the performance and evolution of the principal potable water-utility companies in the country."

The evolution of the development and modernization of water utilities can be evaluated through the makeup of the system of indicators, which employ well-defined standards that permit goals to be reached and contribute to presenting national information in a transparent way.

The National Home Survey (ENH, 2016) is a study carried out by the INEGI with the purpose of logging the primary physical and socio-demographic characteristics of each home and the inhabitants that reside in them. In regards to water service that users receive, the ENH shows results related to:

- The type of water availability in the home

- The availability and frequency of delivery in the home

- The daily availability of water in-home, per federal entity

Granted these results are important, they do not reach the level of detail expected of PIGOO, which is why it is important to perform directed analyses based on operational aspects that allow for the evaluation of users' quality perception and their satisfaction of the service they receive from workers in the office of the water utility in filing any complaint or given procedure.

One important part which has not yet been evaluated in PIGOO is the perception that users have of the water service they receive in their homes, which is why a study — the first of its kind — was carried out in a specific city in the country. This paper presents the results obtained from the town of Patzcuaro, Michoacan, Mexico. (Figure 1). 


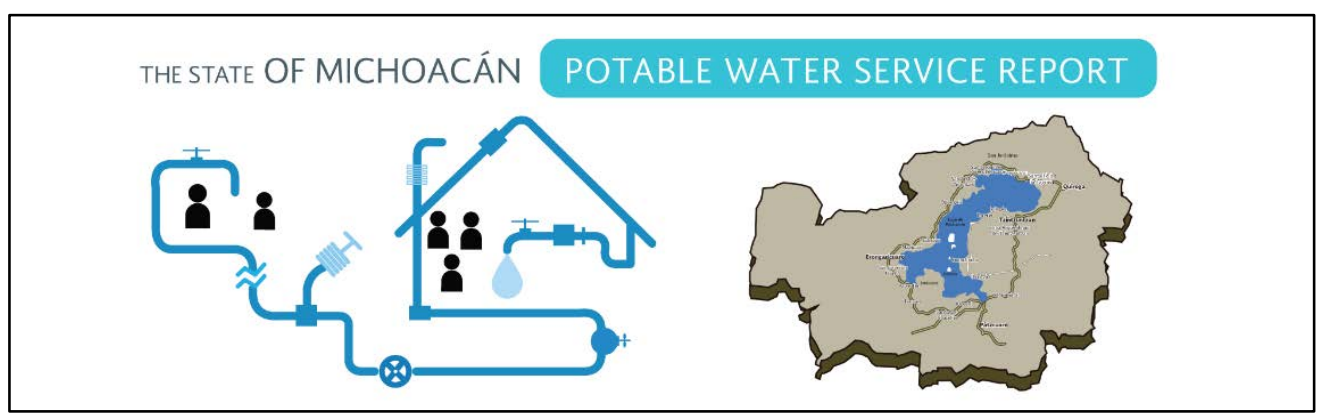

Figure 1 They study was carried out in the town of Patzcuaro, Michoacan, Mexico

\section{Current Dilemma}

In the media, there have been reports (ME, 2015) related to incidents brought about by the discontent of inhabitants over water service issues, sometimes resulting in them taking over water utilities or picketing with poster boards that read "We want efficient public services," or "Out with inept bureaucracy” among others.

Taking these things into account, it was deemed a priority to carry out a market study so as to understand what perception users have of their service, hoping in turn, to orient the water utility concerning problems that users report related to the service.

The perception of service and the value of water is undervalued, according to some news media outlets, 70\% of users do not pay for it (CM, 2016), on top of this, the water tariff is far below what is needed to cover maintenance, operation and management costs.

\section{Diagnostic of the PMSAP commercial area}

In 2016 the IMTA carried out a study of the priority needs detected in the Pro-Maintenance of Potable Water Services (PMSAP) water utility of Patzucaro, Michoacan (IMTA, 2016) in which improvements were sought for potable water, sewerage and treatment services.

The prime objective of this study was to carry out a diagnostic and an action plan for the modernization of the commercial area of this public service provider, prioritizing actions deemed to have profitability benefits and indicators. In this study the following was found:

\subsection{PMSAP finances}

The efficiency indicator for a collections department rates the efficiency between billing and payment, for this study, the billing is patterned off of a users' log and given set tariffs, given that no formal billing/gauging apparatus is present; in this sense, Figure 2 represents the efficiencies achieved by the water utility from 2013 to 2016, bearing in mind that PIGOO reports an average collections efficiency of 70.2\% in 2015 (IMTA, 2017), it can be seen that PMSAP failed to reach this average in any of the years graphed. 


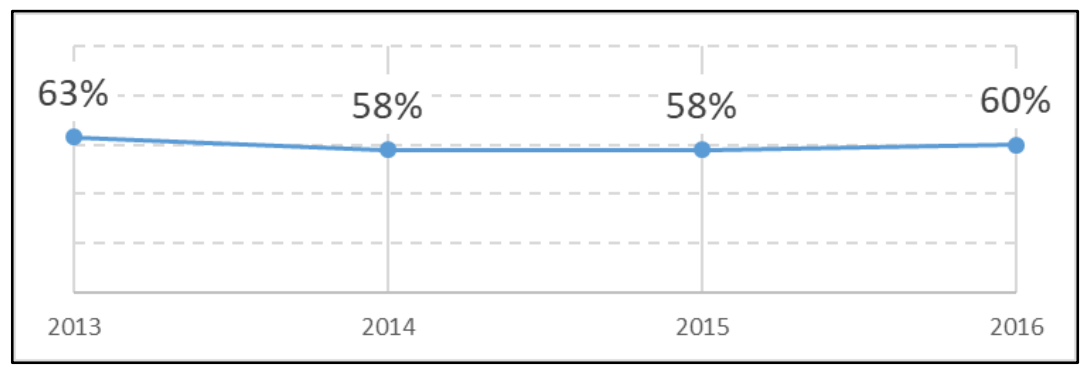

Figure 2 Behavior of collections efficiency, PMSAP

The amount to be billed can be arrived at by dividing by the amount to be paid by the number of water intakes, Figure 3 shows that the highest revenues came in 2016, amounts were converted into euros and dollars to allow for a comparison.

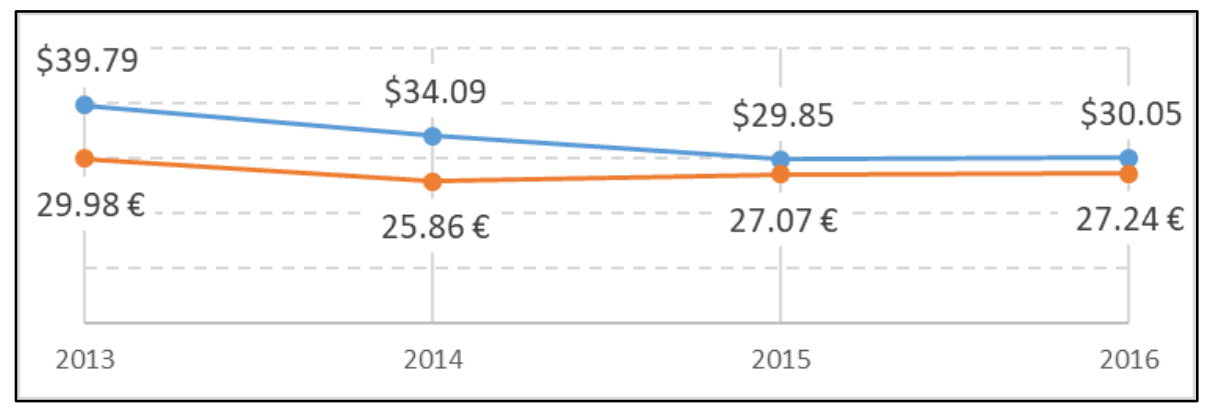

Figure 3 Revenue generated per water intake at PMSAP

Mexico has some of the best and most consolidated water utility operators in Latin America, nonetheless, it is important to mention that there are still some water utilities that have not reached the performance that will permit them self-sustaining operations. Water access, efficiency, as well as the quality of the water and treatment services vary greatly from one town to another, reflecting in large measure, the different levels of development throughout all the country. The topographical and geographical characteristics that Mexico has produces a hydrological condition that obligates strong contrasts in terms of water availability per-capita. In general, the Mexican water and treatment sector has identified some operational issues such as:

- Low technical and commercial efficiency in service provision

- Inadequate water-supply services

- Deficient quality in treatment services, especially in regards to wastewater treatment

- Insufficient coverage in the poorest rural zones

Upon reviewing the behavior of the PMSAP, a general idea can be drawn of the problems many water utilities face throughout the country, hence, it becomes important to know about the users' experience. 


\section{Methodology}

Two studies were used; One analyzes the public image of the institution, that is to say, the way in which users are treated upon requesting service in the PMSAP. The other rates the quality perception of in -home service. Each of the studies was conducted on 100 users in the town of Patzcuaro, Michoacan, Mexico.

The results show deficiencies in the quality, quantity and continuity of the supply, on top of that, there are shortcomings in customer service, collections and the types of rates; the following is an analysis of the information gathered. One thing that stands out, is that in spite of the aforementioned observations, $50 \%$ of people surveyed rated the service favorably and in homes that received service visits, that number ascends up to $60 \%$.

\subsection{Quality analysis in customer service}

This study has the purpose of evaluating how a water utility services its users in relation to: the handling of complaints, customer service in filing procedures, and communication in collections among other things.

The results gathered from the first block report that $90 \%$ of users go to the office solely for purposes of payment.

In the second block, $50 \%$ of users reported receiving immediate attention, and another $30 \%$ reported a short waiting period. According to the results, $50 \%$ report that their procedure required 5 to 10 minutes and $25 \%$ from 10 to 30 minutes. The service offered to workers of the system is rated as regular or good by $40 \%$ of those surveyed.

The third block consists of evaluating the facilities afforded to users by the system. In regards to whether or not the system office was easy to find, only $4 \%$ reported having trouble. Half of the users on which the study was conducted reported having a comfortable wait, while the other half did not. More than 70\% consider that the number of service booths in the PMSAP is sufficient. Almost $90 \%$ of the users that went to the office consider that the customer service representative that attended them was friendly. It is interesting to note that half of the surveyed users rate the service received as good and the other half as regular.

The fourth block of questions is to find out how users perceive the customer service representative of the PMSAP in terms of their capacity. The totality of the users surveyed reported that their representative was knowledgeable about the problem or investigated to find out the solution. Almost all, $95 \%$ reported finding a solution to their problem. In the service given by the representative to the user, $80 \%$ reported that they felt either satisfied of very satisfied.

Upon identifying that the main procedure carried out at the PMSAP is payment of service, they were asked if it was practical to go to an office to carry out payment and almost $65 \%$ responded no. They were asked if the PMSAP should place alternative payment options closer to home and 53\% responded yes. Almost $50 \%$ expressed a preference for having the option of making payments in convenience stores (Figure 4).

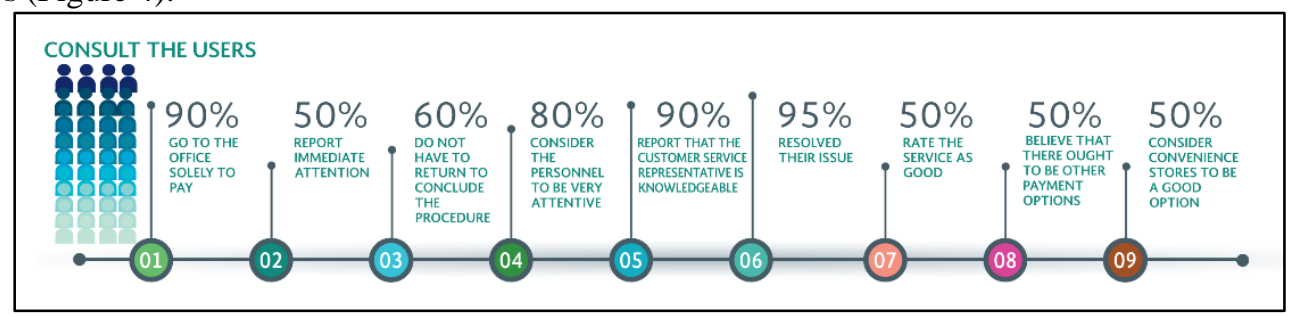

Figure 4 Users' opinions of the system regarding customer service 


\subsection{Analysis of service-quality perception}

This was carried out with the purpose of evaluating how each user perceives the water service they receive in their home. It was divided into three parts, the first analyzes if a procedure has been carried out in the system office, the second block is focused on how the service is paid for and the third evaluates the quality of the service received (Figure 5).

In $70 \%$ of cases, there are no reports of a service failure, of those that have reported a failure, $60 \%$ say that it was resolved within three days or less and the remaining $40 \%$ up to a week or more. Customer service was rated as good or regular by $40 \%$, another $50 \%$ did not wish to reply and the rest consider it to be very poor or did not receive any attention at all.

The second block of questions is related to billing, only 5\% receive their bill at home, while $65 \%$ report that they make an annual payment directly at the system offices often without a bill. They were asked if they preferred metered service, that is to say installing a meter at their intake and more than $70 \%$ did not agree to this. Over $80 \%$ responded as not being willing to increase rates for the purpose of making service improvements.

The objective of the questions in the third block is to evaluate the perception of services offered. For question number one, $60 \%$ of those that answered the questionnaire had intermittent service. Less than half, $40 \%$ received water 7 days a week. The pressure with which water arrives to homes was at $35 \%$, and $45 \%$ report sufficient pressure to always deliver water to a rooftop tank. Clean water provision was reported by $90 \%$. Of those that reported getting dirty water, $80 \%$ could not distinguish if it had color odor or taste. Reported water availability in homes was less than six hours a day in more than $75 \%$ of cases, all the same only $5 \%$ rate the service they receive as being between poor or very poor.
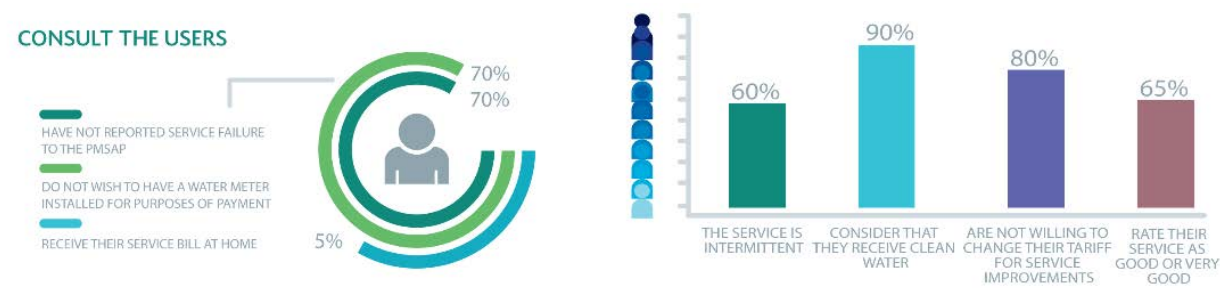

Figure 5 Users' opinions of potable water service at home

\section{Regulation}

The task of supplying potable water to all users of the country irrespective of whether they live in an urban zone or reside in one of the 185000 rural towns with less 2000 inhabitants, is one fraught with difficulty and complexity. It is important to note that these water utility operators are exposed to external factors that limit the performance of these services, one of the most important, given its negative effects is: the influence of local politics in the operation and administration of the water utilities as well as economic factors which weaken the capacity to face commitments in the water production, distribution and supply costs in all of the urban zones.

This situation has given rise to water utilities providing potable water and treatment services under conditions adverse to its citizens and to the water utility as well. The lack of supervision in the quality parameters and the costs of services fuels a vicious cycle in which the lack of revenue due to lack of payment ends up generating low-quality services. In other words, the absence of policies and institutions that might regulate the performance of the water utilities as well as the quality of services provided, provokes a deterioration that turns into a loss of quality of life and wellbeing for citizens, along with a weakening of the public entities in charge of the provision of potable water and treatment services. 
On account of such situations, the IMTA, as the center for public research and technological development which specializes in the problems and needs in the water sector in Mexico, has been developing studies and field investigations which resulted in an institutional proposal to design and install regulatory systems at a state level. It took the challenges, needs and problems that the water utilities face into consideration along with the other parties involved in the provision of these services.

The design proposal for a regulatory system at a state level for the entirety of Mexico presents, illustrates and exemplifies the different stages which must be considered and analyzed carefully for such a creation. Its implementation and operation through a state regulatory entity, with autonomy and impartiality to exercise a regulatory policy establishes an arrangement of controls and incentives for the municipal water utility operators, taking technical, financial, political, social and environmental factors into account.

The developments of regulating potable water and treatment services must be disseminated among the specialists of the sector, decision-makers of the municipal water utilities, state-level civil servants, and local congresses. For that, the IMTA made a book which contains the contextual and conceptual framework for explaining the basic aspects of the regulation of the sector as well as the description of the stages for designing and creating a regulatory system in a federative entity, with this work, the IMTA contributes with public policy orientation for the potable water and treatment sector, the compliance to the human right to water and water security of Mexico (Camacho \& Casados, 2017)

In this sense, regulation is a necessity for improving the services that users receive and an instrument for improving the performance of water utilities responsible for the subsector. At the same time, the regulator, because it is an external agent to those involved and invested directly in the provision of these services, becomes an impartial entity, independent with legal attributions for meeting the needs of users (complaints for poor service) or complaints on behalf of the water utility (suspension of service due to lack of payment) with the understanding that in fulfilling its specialized, legal role, it is guaranteeing the quality of service through its corresponding authorized payment.

\section{Conclusions}

Having a study like the one carried out here, allows the PMSAP to know how users perceive the provision of the services offered as well as to identify their strengths, and improvement areas. These results aim to find a way to compare the interaction and improvement of user services with the watersystem indicators found in PIGOO.

In the Mexican Water Technology Institute there is a proposal for a regulatory system whose principal contribution in Mexico lies in the possibility of gradually reaching physical efficiency and commercial goals in the potable water and treatment systems that are measurable and tangible, irrespective of who the operator is, be it a municipal government, a water utility decentralized from the municipal government, a concessioned associate of the municipality, inter-municipal system, or some other authorized organization, all this with the end of creating and establishing sustainable conditions for water utilities and guaranteeing the quality of public service.

\section{References}

IMTA. (2017). Programa de Indicadores de Gestión de Organismos Operadores (PIGOO). Information provided by Instituto Mexicano de Tecnología del Agua: http://www.pigoo.gob.mx

ENH. (2016). Encuesta Nacional de Hogares (ENH) 2016, principales resultados. Information provided by Instituto Nacional de Estadística y Geografía: 
http://internet.contenidos.inegi.org.mx/contenidos/productos/prod_serv/contenidos/espanol/bvineg i/productos/nueva estruc/promo/enh2016 resultados.pdf

INEGI. (2009). Panorama censal de los organismos operadores de agua en México. Censos Económicos. Information provided by Instituto Nacional de Estadística y Geografía:

http://www.inegi.org.mx/est/contenidos/espanol/proyectos/censos/ce2009/pdf/Mono_Orgs_operad ores agua.pdf

ME. (2015). Monitor Espresso. Toman presidencia de Pátzcuaro Michoacán. Information provided by: https://www.monitorexpresso.com/toman-presidencia-de-patzcuaro-michoacan/

CM. (2016). Cambio de Michoacán. El 70\% de los usuarios del agua potable en Pátzcuaro, no pagan por el servicio. Information provided by: http://www.cambiodemichoacan.com.mx/nota-n14147

IMTA. (2016). Diagnóstico y plan de acciones para la modernización del área comercial del organismo Pro-mantenimiento de los Servicios de Agua Potable. México: IMTA.

Camacho, H., \& Casados, J. (2017). Regulación de los servicios de agua potable y saneamiento en México. Jiutepec, Morelos, México: Instituto Mexicano de Tecnología del Agua.

CONAGUA. (2016). Situación del Subsector Agua Potable, Drenaje y Saneamiento, edición 2016. Information provided by:

https://www.gob.mx/cms/uploads/attachment/file/184667/DSAPAS_2016_web_Parte1.pdf 